\title{
Entre la autonomía y la dependencia. Lobby, clientelismo político e idea de estado en los contextos locales chilenos
}

\author{
David Luján Verón \\ El Colegio de México, Ciudad de México, México. \\ Email: dlujan@colmex.mx
}

\begin{abstract}
Resumen: En este ensayo se buscan debatir algunos aportes de la antropología del estado para señalar cómo los apoyos estatales a las organizaciones vecinales en Chile, delineados en torno a la corresponsabilidad, participación de la sociedad civil y focalización, generan en su implantación a escala local efectos contradictorios y heterogéneos. Basados en una metodología cualitativa y técnicas de entrevistas a profundidad a dirigentes de organizaciones vecinales y políticos en distintos niveles, más observación etnográfica de sus interacciones, se expondrá una práctica que ilustra la actividad local de enlace entre proyectos concursables, ideas sobre el estado y clientelismo político: el lobby. Las conclusiones invitan a pensar el estado desde las políticas públicas en los contextos locales chilenos.

Palabras clave: Antropología del estado, municipalidades de Chile, juntas de vecinos, fondos concursables.
\end{abstract}

\section{Between autonomy and dependency. Lobby, political patronage and idea of state in the local Chilean contexts.}

\begin{abstract}
This essay seeks to discuss some contributions of state anthropology to indicate how state support to neighborhood organizations in Chile, outlined around co-responsibility, civil society participation and targeting, generate contradictory and heterogeneous effects at local scale. Based on a qualitative methodology and techniques of in-depth interviews with leaders of neighborhood and political organizations at different levels, plus ethnographic observation of their interactions, a practice will be presented to illustrate the local activity of linkage between competitive projects, ideas about the state and political patronage: lobby. The conclusions invite to consider the state from public policies in Chilean local contexts.
\end{abstract}

Keywords: anthropology of the state, municipalities of Chile, neighborhood meetings, competitive funds.

\section{Entre autonomia e dependência. Lobby, clientelismo político e ideia de estado nos contextos locais chilenos}

Resumo: Este ensaio procura discutir algumas contribuições da antropologia do estado para indicar como os apoios estatais às organizações de bairro no Chile, delineados em torno da corresponsabilidade, participação da sociedade civil e focalização, gera efeitos contraditórios e heterogêneos na escala local. Com base 
numa metodologia qualitativa e técnicas de entrevistas em profundidade com dirigentes de organizações de bairro e políticos em diferentes níveis, junto com observação etnográfica de suas interações, será apresentada uma prática que ilustra a atividade local de vinculação entre projetos concursáveis, ideias sobre o estado e clientelismo político: o lobby. As conclusões convidam a pensar o estado a partir de políticas públicas em contextos locais chilenos.

Palavras-chave: Antropologia do estado, municípios do Chile, organizações de bairro, fundos concursáveis.

$* * *$

\section{Presentación}

El estado es una de las materias de mayor antigüedad e importancia sobre la que se ha discutido. De forma soterrada o manifiesta, resulta difícil que algún análisis en ciencia social no parta de o problematice aspectos relativos a su naturaleza, funcionamiento, legitimidad, problemas que le aquejan, etcétera. La antropología del estado, en este debate, busca pensarlo relacional y en su recreación cotidiana, lo que significa ir en contra de versiones que lo toman como agente independiente y externo a las poblaciones que gobierna, sede del poder y con un proyecto unificado de dominación. Antes bien, busca “descentrarlo" y considerarlo una organización entre otras, heterogénea y cuya recreación resulta fluida y negociada.

Este trabajo se inserta en esta tradición, preguntándose por los efectos que tienen las políticas sociales a que las organizaciones territoriales y funcionales (juntas de vecinos, centros de madre, clubes de adulto mayor) pueden acceder, los llamados fondos concursables, en la construcción de relaciones clientelares. Los hallazgos de campo son parte de una investigación doctoral en curso más amplia centrada en rescatar algunos aportes de la antropología del estado y el poder para interpelar nociones comunes con que se estudia en clientelismo en contextos locales y Chile en particular. Para ello, nos basamos en una metodología cualitativa basada en observación etnográfica y entrevistas a profundidad a políticos en distintos niveles, secretarios de éstos, dirigentes de organizaciones territoriales y funcionales (juntas de vecinos, centros de madre, clubes de adulto mayor, clubes deportivos), en el período julio 2016-enero 2017, en una comuna chilena.

Si bien omitiremos la referencia al sitio de investigación, resulta conveniente caracterizarla brevemente. Se trata de una comuna urbana, central, y cuya población ronda los 300000 habitantes. Con niveles de pobreza un poco más acentuados que el promedio nacional (14.4\% nacional vs. $17 \%$ en la comuna, según datos de la encuesta Casen 2013), ${ }^{1}$ posee amplias zonas, las más alejadas del centro normalmente, denominadas "tomas" o "campamentos”, con precaria o nula infraestructura y servicios urbanos (agua, pavimentación, plazas, áreas verdes, transporte). De este modo, se trata de una comuna con niveles altos de pobreza y segregación socio espacial. 
Este ensayo está dividido en 4 partes. La primera realiza una reconstrucción contextual y teórica de los fondos concursables en Chile y presenta aquellos a que las organizaciones territoriales y funcionales (de ahora en adelante, llamadas simplemente "vecinales") pueden postular, principalmente los municipales, pues en ellos profundizaremos más adelante. La segunda expone algunos discursos de políticos o sus secretarios en torno al acto de cooperar o postular a las organizaciones a los fondos concursables. La tercera indica el fenómeno del lobby y su relación con la actividad política local. La cuarta concluye, trayendo los aportes de la antropología del estado, anotando algunas claves para pensar el estado a partir de los resultados heterogéneos y contradictorios de las políticas públicas en los contextos locales chilenos.

\section{Aspectos contextuales, teóricos y locales del objeto de estudio}

Las políticas sociales focalizadas se insertan en la región latinoamericana dentro del contexto más amplio de asentamiento del modelo de matriz neoliberal en cuyo discurso se afirma haber impulsado una nueva relación del estado con los pobres, ya no desde el exceso de burocracia y los privilegios de las corporaciones de bienestar social sino desde la democratización y el empoderamiento ciudadano, construyendo el fenómeno de la pobreza como algo medible, objeto de intervención experta, y donde toman relevancia los enfoques de las capacidades y el capital social como estrategias de movilidad social (Agudo, 2015; Vommaro, 2008; 2011).

Haciendo una imagen bastante panorámica del proceso chileno, desde la década del 40 hubo un proceso de expansión del estado social, reflejado en el aumento de los servicios de educación, sanitarios, salud y de vivienda, señalando para algunos tintes de un estado benefactor (Huneeus y Cuevas, 2013; Olmos y Silva, 2010). En los 17 años de dictadura militar comandada por Augusto Pinochet (1973-1990), por el contrario, el gasto social fue reduciéndose y el estado dando paso a los mecanismos de mercado en el acceso de la población a los servicios de educación, salud y previsión social en un marco general de privatizaciones (Garretón, 2012). Además, los apoyos estatales a los más pobres se rearticularon, dándosele un tono focalizado, es decir, individual y temporal: donde la atención estatal se otorga mientras se supera, por medios propios o en conjunto con el estado (haciendo eco de la corresponsabilidad), la situación de pobreza (Huneeus, 2005).

Los gobiernos post-democráticos, inaugurados en 1990, aumentaron las carteras de las políticas de combate a la pobreza y expandieron la focalización junto con mecanismos para medirla, apelando al monitoreo de las familias y sus progresos para, se señalaba, definir más finamente las prioridades en el acceso a los sistemas de apoyo estatal (Martner 2009; de la Maza, 2004). Las instituciones privadas, en esta línea de razonamiento, 
eran igualmente necesarias en la prestación de servicios sociales, pues ello se vinculaba a la descentralización y con ello menos burocracia y corrupción, y más flexibilidad, racionalización y eficiencia de la gestión pública (Garretón, 2012).

El estado, por su parte, se concibió como un buen complemento, y en algunos casos como regulador, de los mecanismos de mercado en la provisión de servicios, sobre todo adecuando la intervención estatal a paliar las externalidades negativas del primero. Por ejemplo, se impulsó el acceso a la vivienda a sectores que no podían acceder al sistema vía mercado, es decir, sujetos sin posibilidad de crédito bancario (Ominami, 2009), o el acceso vía mercado a poblaciones antes excluidas, como en el caso del estímulo de la cotización voluntaria de las dueñas de casa (Varas, 2009). Con todo, estos avances no han tocado los patrones de distribución, fuertemente desiguales, ni el modo de relación del estado con la población (Martner, 2009), centrado en la competencia y el mercado.

Parte de las explicaciones de este fenómeno atienden tanto a señalar las tibias reformas tributarias que se han propuesto (Quiroga, 2009), altamente permisivo a los sectores altos y castigadora de los medios (Garretón, 2012), como al modelo de crecimiento económico, anclado en las exportaciones de materias primas y con baja capacidad de generar empleo, siendo éste precario y de bajos salarios (Huneeus y Cuevas, 2013). La falta de reformas más profundas, a su vez, indicarían tanto la renuncia de los Gobiernos de la Concertación (1990 - 2010) para superar el modelo heredado, como las dificultades para impulsarlos por la oposición de derecha como los enclaves autoritarios heredados de la dictadura y que perviven hasta hoy día (de la Maza, 2004).

Este trabajo utiliza el enfoque de la antropología del estado, que la definimos con un foco de análisis que privilegia el aspecto vivencial y representacional de las prácticas por las que se hacen concretas ideas sobre el estado: su poder, legitimidad, separación frente a una "sociedad", funcionamiento, etcétera. En el mismo sentido, busca señalar efectos paradójicos, mixturas, heterogeneidades y limitaciones, en la aplicación de su “poder” y las lógicas de regateo, cálculo, negociación y disputa que se tejen entre burocracia y población, que pueden derivar en resultados que poco tienen que ver con su diseño desde oficinas centrales (Agudo, 2015; Mitchell, 2015).

Además, problematiza dicotomías generales con que se estudia la política: pasividad vs. resistencia, clientelismo vs. ejercicio de derechos, politización vs. despolitización, e invita a pensar las experiencias e interpretaciones que sobre los centros organizacionales tiene la población local, las redes e intermediarios en que interactúan actores estatales y no estatales o de forma más general las interacciones entre instituciones formales e informales (Nuijten, 2003), así como la imaginación en torno a la colectividad y la vida cotidiana en relación a las tramas estatales (Corrigan, 2002). 
A través de este enfoque, buscamos problematizar los efectos que tienen las políticas sociales de apoyo al financiamiento de las organizaciones vecinales en Chile en la construcción de relaciones clientelares. El vínculo entre ambas dimensiones de análisis (estado, relaciones clientelares), lo establecemos señalando que políticos de distinto cuño impulsan la idea a nivel local, sobre todo entre los dirigentes vecinales, que es a través de ellos que se puede acceder al sistema y la representación política vía fondos concursables, en un ánimo por fomentar relaciones de dependencia y movilización electoral. Los intercambios hacia abajo en torno a esta expectativa, además, se encuentran regulados por normas de reciprocidad y llevados a cabo en un margen más o menos abierto a la creatividad y negociación por los clientes.

De este modo, si el clientelismo puede ser definido como una forma de condicionamiento electoral (Kitschelt y Wilkinson, 2012), aquí nos preguntamos cómo se construye la idea de dependencia y las normas que regulan los intercambios que le rodean, así como las representaciones sobre el estado en juego. Esta opción decanta de no considerar las relaciones clientelares como elementos disfuncionales de la política, poco democráticas u opuestas el ejercicio de la ciudadanía, sino como formas a través del cual el estado se construye, tanto discursiva como materialmente. ${ }^{2}$

La literatura sobre los estudios de clientelismo en Chile abarca distintas dimensiones y focos de análisis. Este trabajo busca dialogar con las vertientes socio-antropológicas donde se visualiza el fenómeno como la extensión de redes de reciprocidad al mundo de la política, es decir, la operación de un capital social asimétrico (Durston, 2005a, 2005b), la personalización de beneficios estatales que se capitalizan políticamente (Barozet, 2003), o el encadenamiento vertical de vínculos de mediación política (Arriagada, 2013). Todos ellos apuntan tanto a la asimetría sobre la que descansa la reproducción de las posiciones que construyen la intermediación clientelar (patrón, intermediario, cliente), como algunas representaciones que sobre la actividad política interactúan entre personeros de la burocracia local, políticos y dirigentes vecinales, como el afecto, sacrificio, y provisión de bienes públicos, temas revitalizados por el trabajo de Auyero (2001).

Dicho lo anterior, entramos al tema de los fondos concursables disponibles a las organizaciones a través del mecanismo de postulación. Éstas no disponen de un ítem o apoyo estatal para la realización de sus actividades, ${ }^{3}$ y normalmente se financian por la vía de la autogestión como apoyos estatales a que puedan acceder previa postulación. Ello significa que deben confeccionar un proyecto, más específicamente, sus dirigentes, debidamente justificado, con montos, tiempos y cotizaciones correspondientes. Por ejemplo, en caso de que se vaya a comprar algún insumo para la organización, como un horno eléctrico, se debe anexar en el proyecto la cotización del precio del mismo horno en tres tiendas distintas.

También, hacen eco de nociones como autonomía y descentralización. Sobre la primera, las bases de postulación señalan que buscan promo- 
ver la inversión -en capital social, infraestructura, capacitación-, e incentivar la autogestión, ${ }^{4}$ con el objetivo de superar la vulnerabilidad social y "la conducta centrada en lo peticionario y demandante y el establecimiento de redes colaborativas barriales". ${ }^{5}$ Aquí lo "peticionario y demandante”, indica un lazo de dependencia sin esfuerzo que habría que extirpar. Sobre el segundo, las municipalidades y gobiernos regionales tienen la capacidad para crear sus propios fondos y los mecanismos para acceder a ellos. Ambos procesos desde las instancias que lo producen tenderían a favorecer una relación con la ciudadanía donde no se le impondría desde el gobierno el tipo de necesidades que debería resolver como las soluciones que le corresponderían, un potente anhelo neoliberal.

Por regla general, postularse no supone el derecho a la obtención del recurso, sino éste depende de la disponibilidad presupuestaria en el tipo de fondo al que se postula, el cumplimiento de ciertos requisitos, ${ }^{6}$ como el puntaje que un grupo de asesores técnicos asigna al proyecto: entre más alto el puntaje, más prioridad para ser asignado. ${ }^{7}$ Los proyectos son recepcionados y seleccionados anualmente, así como los montos que se les destinan, y para el caso de los “ganadores” se pasa a un período de ejecución, es decir, la realización del proyecto, después de lo cual la organización postulante debe entregar una rendición de cuentas por los montos recibidos.

En el caso del sitio de investigación, las organizaciones vecinales pueden postular a tres tipos de fondos municipales: para juntas de vecinos (infraestructura física y mejoramiento urbano, prevención de emergencias, seguridad ciudadana y equipamiento), para organizaciones deportivas (equipamiento e implementación deportiva, capacitación deportiva, infraestructura menor, entre otros), e iniciativas culturales (proyectos de cultura y educación, patrimonio cultural e histórico, pueblos originarios y disciplinas artísticas). Sobre éstos nos concentraremos, aunque valga decir que los mecanismos de operación de los fondos regionales y del estado central son muy similares.

Todas demandan, obligatoriamente, un co-financiamiento de la organización, que puede ir del 10\% al 25\% en dinero, mano de obra y/o materiales. Su selección pasa por tres etapas: una de admisibilidad, ${ }^{8}$ luego de evaluación por una comisión de "expertos” profesionales municipales, y por último aceptación donde, primero, el alcalde da o no su “visto bueno” y luego los concejales votan a favor o no de la totalidad del esquema de priorización propuesto por la comisión evaluadora, no los proyectos en forma individual. Si están a favor la mitad + 1 (regla de mayoría), el esquema propuesto es adjudicado.

El abanico de opciones de financiamiento, dentro de los fondos, es sorprendente y heterogénea: desde instrumentos musicales, máquinas de ejercicios, mejoramiento de áreas verdes, vestuarios folklóricos, hasta reparación de una sede social, inicio de una actividad como amasandería o carpintería, por mencionar algunos. Se parte del supuesto que a cada peti- 
ción hay como correlato una necesidad social (no se pueden postular dos o más organizaciones, en conjunto, al mismo objetivo), lo que hace que, paradójicamente, al promover la sociabilidad y la convivencia, ésta sea privada y privatizante, aunque sea colectiva y se lleve a cabo en el espacio público. La racionalidad política en la ingeniería institucional de este tipo de fondos apoya actividades privadas de grupos atomizados, que desarrollando sus capacidades obtendrían mejores espacios de convivencia y el desarrollo de su capital social.

Además, impide que las organizaciones puedan desarrollar esquemas de funcionamiento más allá de problemáticas puntuales y con apoyos duraderos, ${ }^{9}$ temas sobre los que se ancla el esquema de apoyo vía proyectos. Del mismo modo, es llamativo que los fondos tengan un fuerte sesgo hacia el consumo y el entretenimiento, y que el estado se haga de la legitimidad con la corresponsabilidad (el gobierno pone el dinero, los vecinos el trabajo y la inventiva), desatendiéndose de la responsabilidad por el proyecto bajo la lógica de minimizar la inversión estatal. Por ejemplo: si algo sale mal en la reparación de una sede social, fue debido a una mala ejecución de la empresa constructora, que fácilmente puede desatenderse del tema si se declara en quiebra.

Sin embargo, a nivel local, la forma en que este tipo de discursos es reapropiada por los actores encargados de ponerla en marcha como de quienes la reciben es contradictoria y heterogénea. Conviven, al mismo tiempo, la idea de promoción del esfuerzo como de que los pobres, en virtud de distintas carencias, pueden ser sujetos de asistencia y apoyo estatal, y las lógicas autonomistas impulsadas conviven con otras verticales y orientadas a la dependencia.

\section{La mirada desde arriba sobre los fondos concursables}

En este apartado señalaremos la forma en que se concibe el lazo sociopolítico que anima la relación entre políticos de distinto cuño y dirigentes vecinales en torno a la expectativa de acceso a los recursos estatales vía proyectos concursables, tomando como instrumentos de observación entrevistas a profundidad a políticos como sus secretarios encargados de orientar o involucrarse más directamente en el apoyo a las postulaciones.

En el sitio de investigación, no conocimos alguna organización vecinal que no tuviera la visita continua de algún político (concejal, alcalde, consejero regional, diputado, senador). La mayoría de ellos ofrecían, dentro de la canasta de sus servicios a la población, orientación o la postulación, "en conjunto" con los dirigentes, a los fondos concursables, labor que ejecutaban sus secretarios normalmente: ex dirigentes vecinales, ex trabajadores en la municipalidad, o "expertos" amigos, que disponían de información relevante y capital social que movilizaban en los procedimientos de postulación. Además de dirigirse a políticos, para los dirigentes existían 
otras opciones para asesorarse: a través a un “gestor de proyectos” (un profesional especializado en levantar proyectos que normalmente obtenía su pago no antes, sino después que el proyecto fuera obtenido y no del bolsillo de los dirigentes sino del mismo proyecto, pues en su postulación ya venía un ítem en que se calculaba el cobro de sus asesorías), o algunas empresas que las ofrecían en el marco de "talleres para dirigentes", organizadas en sus mismas instalaciones y sin costo.

En el discurso de los prestadores -políticos y sus secretarios- de este tipo de "colaboraciones" (como ellos nombraban el acto de orientar y postular), por principio de cuentas, se encuentra la opinión que los proyectos requieren, por lo menos, que el vecino conozca información básica sobre los proyectos (qué tipo de fondos existen, cuánto y cómo se postula), y que redactarlos necesita un lenguaje, si bien no técnico, sí claro. Estas situaciones, señalan, no son fáciles de superar, sobre todo por los adultos mayores y población que no tiene internet o no está en contacto con instancias y actores estatales: "tienen ideas, pero no saben cómo aterrizarlas", “a veces están informados que va a salir un proyecto tal fecha, lo que les hace falta es cómo hago ese proyecto”, por ejemplo, aducen un par de secretarias de un diputado de centro-izquierda, ${ }^{10}$ Eugenia y Lucía, cuya oficina distrital se hace cargo de "levantar" proyectos a las organizaciones. Desarrollando al respecto, Eugenia señalaba:

Eugenia: “(...) igual los grupos se complican, por un tema de escribir, por un tema de redactar, porque los números los tienen aquí en la mano, si el tema es cómo llenan el documento, son documentos bastante sencillos, pero para ellos es complicado, entonces ahí entramos nosotros, en hacerle el cuadernillo, copiarle, redactar, traspasar información, que es lo que pide el SENAMA (...)”. ${ }^{11}$

En un tono general, justifican esta actividad de enlace arguyendo tanto la carencia de las organizaciones (de información y conocimiento), como la necesidad social que paliarían los proyectos si llegasen a concretarse. A veces atienden estos temas en sus "oficinas de atención a público”, es decir, los lugares donde atienden regularmente a personas que se acercan para resolver problemas, o en los recorridos que hacen "en terreno": conociendo las necesidades in situ y comprometiéndose a solucionar problemáticas vecinales (infraestructura urbana, inseguridad, microbasurales), o simplemente visitando las organizaciones como una forma en que se recrea un lazo de cercanía y afecto aunque con objetivos de capitalización política, como veremos más adelante:

Lucía: “(...) cuando uno detecta en el caminar, en la visita del propio diputado en las organizaciones y le dicen mire nos llovemos, hace frío porque no tenemos piso, no tenemos loza, ${ }^{12}$ ahí uno los orienta, y les dice, existen estos recursos del estado, por lo tanto, nosotros como oficina los vamos a orientar a que ustedes hagan un buen proyecto, y lo vamos a postular (...)”. 
Aunque algunos discursos señalan que la dificultad para que las organizaciones accedan a recursos estatales vía proyectos se debe a un problema de responsabilidad individual, por ejemplo, "no todos los días están dispuestos a salir de sus poblaciones a buscar el papel” (refiriéndose a los dirigentes como holgazanes o poco comprometidos), la mayoría hace una crítica al lenguaje del estado, que califican como muy técnico y lejano, para la gente. Rodrigo, un consejero regional de centro-izquierda, argumenta cómo la traducción de las “abstractas” políticas estatales se humanizan, es decir, se hacen familiares y concretas, en términos de necesidades sociales:

Rodrigo: “(...) el SERVIU (Servicio Regional de Vivienda y Urbanismo) trabaja con decretos, que si el decreto supremo tal o cual, yo les digo (a la gente) bueno, por ejemplo, el número veintinueve, es compra de vivienda, usada o nueva, trato de decir que ese número es como la solución a un problema, entonces le hablo de la solución, y de la forma, entonces, me caracterizo por entregarle la información como bien para que ellos las entiendan, para que estas políticas de gobierno, la gente las pueda aceptar (...).”

En conjunto con la idea de necesidad y carencia que anima el vínculo hacia abajo, la de esfuerzo también se invoca, mostrándose como un ejercicio de colaboración y apoyo mutuo, y la máquina burocrática, con sus procesos supuestamente impersonales, son imaginados como algo que se hace marchar en base a la voluntad y la dedicación, tanto del político como del dirigente vecinal, a contrapelo de la indiferencia en los espacios estatales, pues en ellos (el municipio y la intendencia regional), reclaman, la espera y la incertidumbre desanima a la gente a continuar con sus trámites.

De este modo, argumentan que, así como ellos se están esforzando por orientar o postular, pues al final de cuentas no es su trabajo -su obligación-, sino una ayuda, el dirigente tiene que cumplir su cuota de responsabilidad, sea teniendo en orden sus papeles o yendo e insistiendo en las oficinas públicas, previa orientación sobre la puerta que hay que tocar. Así, la reciprocidad se construye como una dimensión del juego de expectativas complementarias sujetas a un constante monitoreo, como cuando Eugenia señalaba que "si les dice (el diputado), yo sí los voy a ayudar para que el proyecto llegue a buen puerto, o sea, sean asignados los recursos, tiene que cumplir el dirigente con todo lo que le están pidiendo”. Brenda, la secretaria de un diputado de derecha, de igual modo, refiere que espera que el dirigente también "se mueva”, es decir, se esfuerce, sin lo cual no se vería su interés en sacar adelante proyectos (y, por tanto, no merecería ser apoyado):

Brenda: "(de los papeles) de eso se hacen cargo ellos, la idea es que tú les cooperas, yo no le voy a hacer un proyecto completo a alguien si tampoco se mueve por sus papeles, no se puede y no es correcto (...)." 
En conjunto con los elementos anteriores, resulta pertinente hablar de la autonomía y descentralización proyectada en instancias centrales y que mencionamos en la primera parte del ensayo. También son nociones puestas en juego por actores municipales, como el alcalde. En la ceremonia de entrega de los Fondos Deportivos Municipales 2016, la autonomía, efecto de la concursabilidad, señalaría, es economía y eficiencia de costos en la relación del estado con las organizaciones: ${ }^{13}$

\begin{abstract}
Alcalde: “(...) hoy día, más que postular en la municipalidad para tener un resalto, un paso cebra, para tener una cámara de televigilancia, tener un paradero, hoy día lo que la municipalidad lo que hace es, con esta concursabilidad, es pasar el cheque, que sea de los propios vecinos los que decidan qué es lo que van a hacer, de esta manera vamos más rápido, nos rinde más la plata, nos permite que hoy día entremos en este concepto de decir mira, preocupémonos de la institución porque así tenemos dónde poder sacar recursos que nos permitan el mantener la institucionalidad (...).”
\end{abstract}

Abonando a este argumento, en el video que nos fue facilitado por Lucrecia, dirigente de junta de vecinos, el cual se encontraba en un "pendrive” (que también contenía las bases de postulación a los fondos vecinales) que le había sido regalado por la alcaldía el Día del Dirigente, ${ }^{14}$ se promocionaban los fondos municipales trayendo la voz de algunos dirigentes cuyos proyectos habían sido seleccionados. Ellos mencionaban, desde sus propios territorios, que la lógica de los proyectos recaía en "dar su opinión (la de los vecinos) y decidir en qué se va a invertir el fondo”, y que era fundamental "para la participación de los vecinos, que tomen conciencia que nosotros tenemos que poner la plata y no todo tienen que darlo (el estado)”. Hacer cosas -poner una sede, hacer una escalera-, se continuaba argumentando, era necesario para motivar a la ciudadanía, en sus palabras, darle "incentivos" a la organización comunitaria.

No obstante, a pesar del requerimiento a la colaboración, en la misma ceremonia y el video se hizo patente la significación de las organizaciones como incapaces, por medios propios, de proyectar las actividades de mejoramiento que proyectaban, es decir, por más esfuerzo hay veces que no es suficiente por sí mismo para realizarlas, de modo que se hacía necesario un vínculo con el estado. Así, el alcalde señalaba que sin esos apoyos muchas de las organizaciones “ya nos habrían abandonado”, y en el video admitía un dirigente que el fondo apoya "algo que nosotros no podríamos alcanzar por nosotros mismos."

\title{
El lobby de los proyectos concursables y sus efectos político-electorales
}

En este apartado, mostraremos algunos sentidos atribuidos a la capitalización política y el acceso al estado vía lobby, así como ilustraremos 
efectos que esta práctica tiene en el campo político-electoral, tomando como instrumentos de observación entrevistas a concejales y dirigentes de organizaciones vecinales.

En el ambiente local, políticos de distinta índole buscaban capitalizarse y animar relaciones clientelares, entre muchas estrategias, a través de construir cotidianamente la idea que era gracias a su gestión dentro del estado que los proyectos se conseguían más fácilmente o eran necesarios para que se consiguieran. Si bien sus expectativas de capitalización eran normalmente sabidas por ambas partes (políticos como dirigentes y vecinos), la forma en que se manifestaban solía ser indirectas y sutiles, pues, en primera, es sancionado negativamente que se presentaran como guiados por intereses instrumentales, y en segunda, la mayoría de los dirigentes (sobre todo aquellos que tenían la experiencia de haber tenido proyectos seleccionados), reconocía que los procesos que intervenían para la selección de un proyecto implicaban varias etapas y actores, por lo que era difícil creerle a algún político que se arrogara a señalar que de él solamente dependía la ejecución de un proyecto, o el monopolio de la distribución de recursos estatales.

Aun así, distintas entrevistas y observación etnográfica dan cuenta de cómo los actores políticos van generando distintos subterfugios para hacer saber que los proyectos dependen de ellos y que esperan que los favores otorgados puedan ser reciprocados con votos. Los dirigentes, por su parte, reciben estas expectativas de formas diferenciadas y también pueden ser creativos e impulsar demandas en este juego clientelar.

En el sitio de investigación, algunos dirigentes vecinales señalaban hacer continuamente "lobby" con políticos, especialmente concejales, es decir, consiste en una práctica nombrada por los propios actores y es apropiada de otros contextos (el lobby es una palabra bien conocida dentro la actividad política dentro del estado para gestionar intereses particulares y por lo menos en Chile es regulada y considerada una práctica "legítima"). ${ }^{15}$ Para los dirigentes entrevistados, hacer lobby significa conversar con un político para que impulse o agilice tu proyecto dentro de las instancias estatales bajo la idea que son ellos los que votan individualmente, autorizan los proyectos, o por lo menos tienen más contactos, información o recursos que pueden movilizar para hacer que un proyecto resulte seleccionado. Sin embargo, como vimos en el primer apartado, los concejales no votan por los proyectos individualmente sino por el esquema de priorización propuesto por una comisión técnica, por lo que éstos aprovechaban que esta información no era del dominio común en los dirigentes y se hacían ver como los enlaces necesarios para hacer marchar la máquina estatal, situación que se correspondía con los discursos de algunos dirigentes que señalaban que políticos a distinto nivel (diputados, consejeros regionales, concejales), tenían "la sartén por el mango" en lo que se refiere a definición de proyectos.

Así, Enrique, un concejal de centro-izquierda argumentaba que, posteriormente a la selección de los proyectos municipales, acostumbraba de- 
cir en sus visitas a distintas organizaciones que había apoyado la selección de sus proyectos, señalando: "bueno, yo vi en la lista de los proyectos a la organización (nombre de la organización que visita en ese momento) y pues, levanté la mano”. En ocasiones hacen llamadas por teléfono, como lo expresaban dos dirigentes de club de adulto mayor, Cristina y Graciela, respectivamente: "los mismos concejales te llaman, Cristina, vimos un proyecto donde estás postulando, no te preocupes nosotros votamos por ti”, “el (Rodolfo, concejal de centro izquierda) dice, comadre, faltaba un voto y era el mío, yo voté por su proyecto (...) yo le digo, ya, yo te las creo todas (ironizando, pues sabe que no es así pero no le ofende recibir una mentira).”

Cuando hacían lobby, los dirigentes acostumbraban justificar su proyecto en términos de necesidades sociales: beneficiaría a mucha gente, permitía resolver una necesidad fuertemente sentida, o llevaría alegría o entretención a la población, y en especial a los niños y/o los adultos mayores, los grupos sociales escenificados como los más necesitados. Normalmente, señalaban que las autoridades respondían asintiendo y señalando que, por ellos, no encontrarían problema en que su proyecto fuera aprobado.

El lobby también implica para los dirigentes ir a hablar con un político dependiendo a qué comisión pertenezca, ${ }^{16}$ por ejemplo, si están postulando a un proyecto de cultura, hay que ir a hablar con el concejal presidente o que pertenezca a esa comisión. En este sentido, hay veces en que los dirigentes llegan a un nivel de cálculo muy sofisticado sobre cuál concejal puede apoyarlos y cuál no, o cómo la influencia no solo opera de abajo hacia arriba sino entre los personeros del estado. María, una dirigente de junta de vecinos, por ejemplo, argumentaba después de haber hecho varias postulaciones:

María: “ (...) Primero le pedí a Gabriel (concejal de centro-izquierda), era de Finanzas, el Enrique (concejal de centro-izquierda) que es de, Régimen Interno, que es el que ve los proyectos, tengo dos, contemos que el alcalde no está conmigo (porque a María, aunque se define como apolítica, se le vio trabajando en campaña por el alcalde que recién acaba de perder las elecciones municipales, y eso la lleva a considerar que el nuevo alcalde será reticente a su cercanía), Jorge (concejal de derecha) bien, tres, Pedro (concejal de derecha), cuatro, Nora (concejal de derecha) cinco, le dije ayúdanos con el Salvador (concejal de izquierda y que en la mentalidad de María puede influenciar a Salvador porque es esposo de Nora, a pesar de pertenecer a conglomerados políticos distintos), ahí seis, a Camilo (concejal de derecha) se lo puede manejar el Pedro (porque, dice, pertenecen al mismo partido) (...)”.

Otro dirigente, Joaquín, presidente de un club de adulto mayor, señalaría en los mismos términos:

Joaquín: “(...) a Enrique le digo, mira tengo este proyecto, para que me respaldes, ahora depende de ti, a Pedro igual, ellos trabajan para 
que el proyecto salga, Rodolfo es muy allegado al club, es el presidente de la Comisión de Deportes, es como tener un combo dado (...)”.

En ambos discursos, se ve con más detalle lo que está en juego en las expectativas de acceder al estado vía lobby. María y Joaquín señalan que el grado de control que pueden tener sobre los concejales, y entre éstos últimos, depende de la cercanía, que es indicada en relaciones conyugales o partidarias, y que si bien los proyectos no dependen de una persona sino varias, los dirigentes pueden influir en la concertación de intereses, es decir, la votación que hacen los concejales por el esquema de priorización, hablando con los más afines y esperando que ellos extiendan la influencia con sus afines, respectivamente. Además, es interesante hacer notar el uso de María de "se lo puede manejar", como una forma de señalar que los actores estatales desarrollan unos con otros no solo cercanía sino también conocimiento mutuo sobre el que intitulan la capacidad de control, y es justamente este proceso el que ella busca movilizar hacia arriba.

Joaquín, además, cuando expresa "ahora depende de ti”, invoca la asimetría de la intermediación política y hace concreta la capacidad de decisión, "el poder" del concejal, dentro el estado. En ambos, por último, se recrea una política personalizada más allá de (a pesar) de la impersonalidad que desde instancias centrales se supone anima la postulación a proyectos. Todas estas observaciones apuntan a la influencia, que depende del grado de cercanía con uno u otro político, el detonador, desde el punto de vista de los dirigentes vecinales, del acceso al sistema y la representación política.

La capitalización de los concejales vía proyectos no solo consiste en animar expectativas de dependencia en torno al lobby, sino en distintos momentos en que "dan la lucha" para que los proyectos salgan en el contexto de alguna dificultad. Enrique señalaba, por ejemplo, que no estaba interesado tanto en destacar su capacidad de decisión frente a los proyectos que eran seleccionados como en los que no eran seleccionados, éste era su nicho de capitalización electoral (detectado por él como el más rentable). Esto significaba que con dirigentes cercanos cuyos proyectos habían sido detenidos por alguna cuestión "formal", es decir, de procedimiento administrativo (no se anexó alguna fotocopia, la firma de los socios, por ejemplo), se comprometía a movilizar la máquina estatal "en beneficio de la gente”.

Como un ejemplo, argumentaba en torno una vez que dio "la lucha”: el proyecto cultural de Martha, una dirigente de organización social-cultural que recientemente había postulado a un fondo cultural y había sido rechazado porque no habían sido anexados algunos documentos. ${ }^{17}$ Sin argumentar en qué había consistido su lucha, ${ }^{18}$ sí indicó la expectativa electoral que la movilizaba: "los siete proyectos (que ahí se adjudicaron) fueron favorecidos gracias a mi pelea. Allá son por lo menos 50 votos". 
Pasando al impacto que tiene esta idea de dependencia en el campo político-electoral, había ocasiones en que los dirigentes afirmaban que, como una forma de agradecer el apoyo por los proyectos, votaban ellos o animaban a votar a su familia, conocidos o integrantes de la organización que lideraban por el concejal que los había apoyado. A veces y dentro de relaciones con un grado alto de intercambio (no solo económico sino también político y afectivo), esto iba a acompañado de un compromiso mayor que involucraba organizar algunos actos de campaña dentro de sus territorios, repartir propaganda, ser vocal de mesa en la jornada electoral para "defender" los votos del candidato, etcétera.

En el mismo caso del proyecto cultural, Martha señalaba que como una forma de agradecimiento a Enrique lo nombró presidente del jurado del Festival Cultural al que había accedido vía el proyecto por el que concursó y en un inicio fue rechazado, además de, llegado el momento electoral, se puso de acuerdo ella y su directiva en relación al voto:

Martha: “ (...) mira entre la directiva nos pusimos de acuerdo, presidente secretario y tesorero, así no quedamos mal con nadie, tampoco tú tienes que decirles no se preocupe, yo voy a votar por ti, nada, si el voto es tuyo, pero nos organizamos, tú vota por éste, así no quedamos mal, y si tenemos que golpear puertas humildemente, porque nosotros estuvimos con ellos, ellos se sienten recompensados, lo dividimos entre Enrique, Alberto (aspirante a concejal), Lidia (aspirante a concejal), Pedro, también estaba Javiera (aspirante a concejal), pero creímos que no iba a salir, por eso no la votamos (...)".

En las palabras de Martha se ve con claridad un proceso más general en que los dirigentes reconocen que frente a políticos no dicen directamente que van a votar por ellos (decirles, como ella, "no se preocupe, yo voy a votar por ti”), recreando la asunción que el voto es individual, al mismo tiempo que expresan la preocupación porque salgan las autoridades que les han cooperado, que les han permitido darle una mascada al estado, para que lo sigan haciendo, y del que se despliegan distintas estrategias para concertar el voto. Además, la expectativa de reciprocidad en que se funda el lazo de apoyo político y que no espera romper si Eugenio pensase que no fue recompensado en la votación.

En la división entre candidatos que hace Martha, en tercer lugar, se expresa la meticulosidad de los cálculos en que se dialoga el voto. Algunos dirigentes eran muy sofisticados en desarrollar que en la división tendían a tener más peso los que, además de haberles cooperado más, tenían mayores posibilidades de ser elegidos (ya eran autoridades en el cargo por lo que era suficientemente conocidos y tenían recursos económicos para desplegar en campaña, normalmente). De aquí que en la división de Martha hubo aspirantes a concejal que, a pesar que habían cooperado, se había "decidido" no votar por ellos, porque creían "que no iba a salir". 
La expectativa de capitalización electoral, por último, era un recurso del que los dirigentes a veces echaban mano en sus relaciones con concejales para intitular demandas dentro del estado, esto es, si a los políticos les interesan los votos, señalaban los primeros, ellos poseían un recurso que los hacía apetecibles a los segundos: el acceso a las organizaciones que lideraban y el potencial caudal de votos que le correspondía; sobre él recaía mucho de su poder y las cosas que podrían lograr. Al respecto, Manuel, un dirigente de una junta de vecinos recién iniciando su período como presidente, contaba cómo esperaba jugar con el acceso a su organización y hacer un reconocimiento público al concejal que esperara lo orientara en las postulaciones, en la expectativa que hacer esta mención tendría efectos electorales. Además, menciona que este reconocimiento iría condicionado al apoyo prestado:

Manuel: “ (...) en el FONDEVE, Enrique (el concejal) nos va a guiar, le voy a pedir ayuda, y cuando llegue el momento, que se haya concretado la cosa (que el proyecto haya sido seleccionado), voy a decir ya, gracias al concejal que todos ustedes tuvieron su proyecto, ayudó en esto y lo otro, le pones cualquier color a la weá, ${ }^{19}$ cosa que la gente vea chuta ${ }^{20}$ este weón ${ }^{21}$ nos ayudó, démosle el voto, después, ¿él qué puede decir? quiero su voto, nada más (...) pedir un aplauso, dar las gracias porque en todos los esfuerzos que hicimos, el hombre la lleva (el concejal) (...).”22

\section{Conclusiones. Re-articulando la construcción del estado desde las relaciones clientelares}

Este apartado tiene el objetivo de anotar algunas claves sobre los resultados heterogéneos y contradictorios de las políticas públicas, los aportes de la antropología del estado para pensar las relaciones clientelares y su lazo con la personalización de la política en el contexto chileno.

La autonomía que desde instancias centrales es imaginada, en los contextos locales es reapropiada por lógicas clientelares. Estas sin duda invocan y hacen concreto el esfuerzo, pues hay un cofinanciamiento que se debe cubrir y quienes participan de la orientación y postulación de los proyectos piden que los dirigentes también hagan parte del trabajo con base en normas de reciprocidad: toquen puertas, consigan papeles, estén al pendiente. Sin embargo, para los actores locales la idea de esfuerzo se compagina la de necesidad de asistencia, que legitima el lazo sociopolítico y estructuralmente crea la expectativa de un estado que asista y solucione problemas.

Los actores políticos se reapropian de esta expectativa y la alimentan para capitalizarse con la población local. La descentralización, vista en este ensayo como el debilitamiento de facultades del estado central para otorgársela a los gobiernos locales como privados, da lugar 
no solo a una economía de costos y la desresponsabilización e las políticas de apoyo a las organizaciones vecinales sino también a la creación de nichos de poder sostenidos sobre las necesidades sociales que los proyectos encarnan.

La creación del poder, trayendo los aportes de Nuijten (2003), significa la imaginación que sobre la fortaleza del estado moviliza creencias y prácticas y que, en un círculo que se autorrefuerza, contribuye a la fetichización de este "centro poderoso" y lo constituye como el espacio donde todo se puede lograr, donde no hay límite para la expresión de deseos. Para el tema que aquí nos ocupa, el lobby es una adecuada ilustración de este fenómeno: la asimetría de que parten dirigente y concejal tiene como base la fetichización de la intermediación de estos últimos con objeto de acceder, por lo menos un sector de la población, al sistema y la representación política.

Luego, la influencia que sostiene esta práctica da lugar a que dirigentes como políticos recreen cotidianamente "ciudadanías diferenciadas”, es decir, distintas posiciones y asimetrías encuentran correlatos en la desigual capacidad para tener voz y voto en las oficinas públicas (Wanderley, 2009). Este tipo de recurso invoca una relación personal, de cercanía y conocimiento mutuo, que es otra forma de ver cómo el estado es humanizado a través de relaciones locales.

En el lobby y la influencia que le supone el tiempo juega un papel central en esta diferenciación (Buchely, 2015), pues una buena parte de la práctica del lobby se justifica en términos de agilización de los proyectos. Luego, como una forma de devolver el favor por las orientaciones prestadas (de nuevo, normas de reciprocidad), o por la idea que es a través de ciertos concejales que pueden acceder a ciertos recursos del estado (elemento sobre el que se basa la asimetría en la posición dirigente-concejal), los dirigentes participan de las relaciones de subordinación haciendo de la asimetría un recurso para intitular demandas. Estos elementos dan cuenta de cómo en las relaciones clientelares los clientes también participan creativamente.

Si bien los estudios sobre clientelismo en Chile ya han destacado la personalización de la política que le constituye, no se han destacado con profundad su vínculo con el estado. Con los hallazgos aquí mostrados, las políticas públicas que financian organizaciones vecinales incentivan las redes colaborativas, como señalan las bases de postulación, pero mediatizadas por mecanismos clientelares y de un perfil sectorializado, bajo el alero de demandas domesticadas que se centran en temas de consumo y entretenimiento, y donde se mina la posibilidad de promover derechos de ciudadanía social y la formación de un sujeto con capacidad de interpelar los mecanismos de distribución estatal. 


\section{Agradecimientos}

La información aquí presentada forma parte de una investigación doctoral en curso, conducente a obtener el grado de doctor en sociología por El Colegio de México. El autor agradece el apoyo para su realización al Consejo Nacional de Ciencia y Tecnología (CONACYT), de México, como en Chile al proyecto FONDECYT regular No. 1160984, “¿Malas prácticas o “aceitar la máquina”? Las instituciones informales en tiempos de cambios políticos y su impacto en la democracia chilena (2016-2019)”, dirigido por Emmanuelle Barozet. 


\section{Notas}

1 “Informe de Desarrollo Social 2015”. Ministerio de Desarrollo Social. http:// www.ministeriodesarrollosocial.gob.cl/pdf/upload/IDS2.pdf

${ }^{2}$ Debemos esta reflexión del análisis sobre la corrupción a Akhil Gupta (2015).

${ }^{3}$ Las juntas de vecinos centran sus actividades en la gestión de algunas problemáticas con las autoridades locales (pavimentación, iluminación, seguridad, etcétera). Los clubes de adulto mayor y centros de madre son espacios más volcados hacia la sociabilidad de los adultos, especialmente los mayores, donde semanalmente se reúnen a tomar once, jugar lota (lotería) o bingo, y a veces reciben la visita de algún empleado de la municipalidad para efectuar talleres (costurería, repostería, por ejemplo, para el caso de centros de madre, o en torno a la prevención de la salud en el caso de los centros de adulto mayor). Los clubes deportivos, como su nombre lo indica, son espacios dedicados al fomento del deporte, y pueden formar ligas locales y apoyar a sus integrantes (que en el contexto de estas organizaciones son llamados "socios”), con la compra de insumos para los juegos (camisetas, balones, calcetas). Todos estos espacios se encuentran en interacción constante con políticos que les proveen algunos insumos para su funcionamiento: juegos de vasos, teteras, tortas para la celebración de los aniversarios de las organizaciones, premios para bingos, etcétera. Si bien el tema de este ensayo son los fondos concursables, las interacciones entre autoridades y dirigentes no se agotan en ellos. Al contrario, se trata de una comuna en que dirigentes vecinales y autoridades intercambian un sinnúmero de cosas, desde los insumos ya mencionados hasta otros más personales, como cartas de agradecimiento, diplomas, o regalos de cumpleaños.

4 “Bases Fondo Deportivo Concursable. Llamado 2016”. Documento obtenido de la página electrónica de la municipalidad del sitio de investigación.

5 "Bases Administrativas y Técnicas de Postulación al Fondo de Desarrollo Vecinal (FONDEVE)”. Documento obtenido de la página electrónica de la municipalidad del sitio de investigación.

${ }^{6}$ Que la organización se encuentre vigente, un cronograma de actividades, entre otros.

${ }^{7}$ Este puntaje se asigna en función de la factibilidad del proyecto, relación costoseficiencia, si es compatible según una pauta de evaluación definida, entre otros criterios.

${ }^{8}$ Para ser admitido el proyecto, la organización no debe tener rendiciones de cuentas pendientes, que su directiva esté vigente, la firma de un número de socios que avalan la presentación del proyecto, entre otros requisitos.

${ }^{9}$ En el plano general de las políticas sociales, la pertinencia de esta discusión es presentada por de la Maza (2004).

${ }^{10}$ A partir de ahora, usaremos las etiquetas "centro-izquierda” y "derecha”, cuando introduzcamos el nombre de algún político, para contextualizarlos en el panorama político comunal. Aquellos que se encuentran en la primera categoría pertenecen a la Democracia Cristiana (DC), Partido por la Democracia (PPD), Partido Socialista (PS) y Partido Comunista (PC), mientras que los de la segunda pertenecen a Renovación 
Nacional (RN) y la Unión Demócrata Independiente (UDI). Valga decir, éstos no son los partidos que abarcan el espectro político chileno sino los domicilios de los políticos aquí presentados.

${ }^{11}$ SENAMA es el acrónimo de Servicio Nacional de Adulto Mayor que, como su nombre lo indica, abre fondos para los clubes de adulto mayor.

${ }^{12}$ Loza refiere a utensilios de vajilla.

${ }^{13}$ Más ampliamente, la ceremonia ocurrió en la sala principal del edificio municipal donde festivamente se entregaron los cheques a los dirigentes cuyos proyectos habían sido seleccionados ese año (2016), de la mano de distintas autoridades locales, después de lo cual hubo un "brindis de honor".

${ }^{14}$ El "Día del Dirigente Social y Comunitario”, se celebra en Chile el 7 de agosto.

${ }^{15}$ Más información en: “Ley de lobby”. http://www.bcn.cl/leyfacil/recurso/ley-dellobby

${ }^{16}$ Las comisiones son instancias al interior de los consejos municipales o regionales dedicados a tratar temas previamente a las sesiones de concejo: espacios donde se reúnen concejales y alcalde o consejeros regionales e intendente, a debatir y tomar acuerdos municipales o regionales, respectivamente. Las comisiones están divididas según áreas de competencia: deportes, cultura, seguridad ciudadana, por ejemplo. Para el caso de las municipalidades, cada una tiene su propia forma de regular el trabajo en comisiones. Para más información, véase la "Ley Orgánica Constitucional de Municipalidades”. https://www.leychile.cl/Navegar?idNorma=251693

${ }^{17}$ Hablando después con Martha, señalaba que había introducido de forma incorrecta información en un anexo, después de lo cual le contó al concejal, es decir, hizo lobby.

${ }^{18}$ Tema que requiere su propia interpretación. El silencio sobre este acto para nosotros indica que los contactos y la influencia que el concejal movilizó dentro del estado no pueden ser publicitados pues eso quiebra su propia posición de intermediario, es decir, en caso que se publicitasen, los dirigentes podrían ir con estos actores (quizá ubicados en posiciones de mayor jerarquía y capacidad de control de recursos públicos, como el alcalde), y tratar de influirlos a ellos sin recurrir al concejal.

19 "Ponerle color", significa exagerar un evento, hacerlo rocambolesco. Por otra parte, weá puede denotar una cosa, situación o cuestión, y puede reemplazar casi cualquier predicado.

20 "Chuta" es una expresión que indica sorpresa al tiempo que lamentación o disgusto, por ejemplo, “!chuta, olvidé mi cartera!”. En este contexto, refiere simplemente a sorpresa.

21 “Weón” es un sustantivo que se usa ambiguamente. En este contexto, indica la relación de familiaridad y cercanía que el dirigente señala tener hacia Enrique, el concejal.

22 “El que la lleva”, significa "el que lidera, manda”. 


\section{Bibliografía}

Arriagada, E. (2013). Clientelismo político y participación local. El rol de los dirigentes sociales en la articulación entre autoridades y ciudadanos en Santiago de Chile. Polis. Revista Latinoamericana, (36). Recuperado de: http://polis.revues.org/9389

Agudo, A. (2015). Una etnografía de la administración de la pobreza. La producción social de los programas de desarrollo. México D.F, México: Universidad Iberoamericana.

Auyero, J. (2001). La política de los pobres: las prácticas clientelistas del peronismo. Buenos Aires, Argentina: Manantial Ediciones.

Barozet, E. (2003). Movilización de recursos y redes sociales en los neopopulismos: hipótesis de trabajo para el caso chileno. Revista de Ciencia Política, XXIII (1), 39-54. Recuperado de: http:// www.redalyc.org/articulo.oa?id=32423104

Buchely, L. et al. (2015). Imaginarios sobre prácticas judiciales en Cali, Colombia. Íconos, Revista de Ciencias Sociales, (52). Recuperado de:http://revistas.flacsoandes.edu.ec/iconos/article/view/1687/1302

Corrigan, P. (2002). La formación del estado. En J. Gilbert y D. Nugent (comps.), Aspectos cotidianos de la formación del estado. La revolución y la negociación del mando en el México moderno. México, México D.F: Era.

De la Maza, G. (2004). Políticas públicas y sociedad en Chile: El caso de las políticas sociales (1990-2004). Política (43), 105-148. Recuperado de: http://www.redalyc.org/articulo.oa?id=64504306

Durston, J. (2005a). El clientelismo político en el campo chileno (primera parte): La democratización cuestionada. Ciencias Sociales online, II (1), 1-30. Recuperado de:http://www.uvm.cl/csonline/2005_1/pdf/ clientelismo.pdf

Durston, J. (2005b). El clientelismo político en el campo chileno (segunda parte): Cambios en las formas predominantes de clientelismo. Ciencias Sociales online, II (2), 1-22. Recuperado de:http://www.uvm.cl/ csonline/2005_2/pdf/clientelismo2.PDF

Garretón, M. (2012). Neoliberalismo corregido y progresismo limitado. Los Gobiernos de la Concertación en Chile, 1990-2010. Santiago, Chile: Arcis-Consejo Latinoamericano de Ciencias Sociales (CLACSO).

Gupta, A. (2015). Fronteras borrosas: el discurso de la corrupción, la cultura de la política y el estado imaginado. En P. Abrams, A. Gupta y T. 
Mitchell. Antropología del estado (pp. 71-144). México D.F, México: Fondo de Cultura Económica.

Huneeus, C. (2005). El régimen de Pinochet. Santiago, Chile: Editorial Sudamericana.

Huneeus, C. y R. Cuevas (2013). La doble ruptura de 1973, cuarenta años después. La democracia semisoberana. Política / Revista de Ciencia Política, 51 (2), 7-36. Recuperado de: http://www.revista politica.uchile.cl/index.php/RP/article/viewArticle/30154

Kitschelt, H. y S. Wilkinson (2012). Vínculos entre ciudadanos y políticos. Una introducción. Documentos de trabajo, (11). Recuperado de: http:/ / a merico.usal.es/iberoame/sites/default/files/ Documento_Trabajo11_Kitschelt_y_Wilkinson.pdf

Martner, G. (2009). Algunos resultados de la política social chilena desde 1990. En Y. Quiroga y J. Ensignia (Eds.), Chile en la Concertación (1990-2010). Una mirada crítica, balance y perspectivas. Tomo I (pp. 159-192). Santiago, Chile: Friedrich Ebert Stiftung. Recuperado de: http://www.chile21.cl/wp-content/uploads/2012/08/Chile-en-laConcertaci\%C3\%B3n-1990-2010.-Una-mirada-cr\%C3\%ADtica-balance-y-perspectivas.pdf

Mitchell, T. (2015). Sociedad, economía y el efecto del estado. En P. Abrams, A. Gupta y T. Mitchell. Antropología del estado (pp. 145-187). México D.F, México: Fondo de Cultura Económica.

Nuijten, M. (2003). Power, community and the state: the political anthropology of organisation in Mexico. Londres, Inglaterra: Pluto Press.

Olmos, C. y R. Silva (2010). El rol del Estado Chileno en el desarrollo de las políticas de bienestar. Expansiva, (27), Recuperado de:http:// www.expansiva.cl/media/publicaciones/indagacion/documentos/ 2010070914 1427.pdf

Ominami, C. (2009). Chile: una transición paradojal. Notas para un examen crítico. En Y. Quiroga y J. Ensignia (Eds.), Chile en la Concertación (1990-2010). Una mirada crítica, balance y perspectivas. Tomo II. Santiago, Chile: Friedrich Ebert Stiftung. Recuperado de: http:// library.fes.de/pdf- files/bueros/chile/07499.pdf

Quiroga, Y. (2009). De modelo ejemplar a modelo de enmiendas: el sistema de pensiones de Chile. En Y. Quiroga y J. Ensignia (Eds.), Chile en la Concertación (1990-2010). Una mirada crítica, balance y perspectivas. Tomo I. Santiago, Chile: Friedrich Ebert Stiftung. Recuperado de: http://www.chile21.cl/wpcontent/uploads/2012/08/Chile-en-laConcertaci\%C3\%B3n-1990-2010.-Unamirada- cr\%C3\%ADtica-balance-yperspectivas.pdf 
Varas, A. (2009). Del éxito al fracaso concertacionista. El gobierno de Michelle Bachelet y la derrota electoral de 2010. En Y. Quiroga y J. Ensignia (Eds.), Chile en la Concertación (1990-2010). Una mirada crítica, balance y perspectivas. Tomo II. Santiago, Chile: Friedrich Ebert Stiftung. Recuperado de: http://library.fes.de/pdf-files/bueros/chile/ 07499.pdf.

Vommaro, G. (2008). Combatiendo el clientelismo. Los expertos en control de políticas sociales de lucha contra la pobreza. En IX Congreso Argentino Antropología Social. Facultad de Humanidades y Ciencias Sociales, Universidad Nacional de Misiones, Posadas. Recuperado de: http://www.aacademica.org/000-080/289.pdf

Vommaro, G. (2011). La pobreza en transición. El redescubrimiento de la pobreza y el tratamiento estatal de los sectores populares en Argentina en los años 80. Apuntes de investigación del CECYP, (19), 45-73. Recuperado de: http://www.apuntescecyp.com.ar/index.php/apuntes/article/view/336/316

Wanderley, F. (2009). Prácticas estatales y el ejercicio de la ciudadanía: encuentros de la población con la burocracia en Bolivia. Íconos. Revista de Ciencias Sociales, (34). Recuperado de: http:// www.flacso.org.ec/docs/i34wanderley.pdf

\section{Entrevistas:}

- Eugenia y Lucía, secretarias de un diputado de centro-izquierda

- Brenda, secretaria de un diputado de derecha

· Rodrigo, consejero regional

• Enrique, concejal

- Cristina, Graciela y Joaquín, dirigentes de clubes de adulto mayor

- María y Manuel, dirigentes de juntas de vecinos

• Martha, dirigente organización social-cultural

Recibido: $\quad 06.09 .17$

Aceptado: 03.11.17 